\title{
GÊNERO NO DESIGN: A REPRODUÇÃO DOS IDEAIS DE MASCULINIDADE E FEMINILIDADE
}

Talita Meier Marques Rodrigues

Pontifícia Universidade Católica do Rio de Janeiro

talitameiermr@gmail.com

Denise Berruezo Portinari

Pontifícia Universidade Católica do Rio de Janeiro

denisep@puc-rio.br

Resumo: Este trabalho propõe uma discussão sobre a manifestação dos ideais de masculinidade e feminilidade, principalmente nos produtos para cuidado pessoal. Buscamos compreender como estes estereótipos se apresentam no imaginário social e de que forma o design dá corpo a eles. A atribuição de significado às formas, materiais, cores e nomes utilizados no design de produtos demonstra sua contribuição para a (re)produção das diferenças de gênero com as quais a cultura material trabalha. Esta reprodução de estereótipos não é idealizada conscientemente, mas favorece a manutenção de um sistema de diferenciação pautada em ideais que possuem origens socioculturais. Neste artigo, procuramos interpretar os procedimentos do design sob uma perspectiva da semiologia, compreender como se dá a construção das diferenças de gênero e identificar, por meio da análise de alguns produtos, a manifestação das características socialmente atribuídas como masculinas ou femininas. Por fim, observamos iniciativas de que utilizam o design como meio para o borramento das fronteiras de gênero.

Palavras-chave: gênero, desenho industrial, cultura material, semiologia.

\begin{abstract}
This paper aims to discuss the manifestation of masculinity and femininity ideals, mainly in self-care products. We seek to understand how these stereotypes present themselves in the social imaginary and how design gives them shape. The assignment of meaning to shapes, materials, colors and names used in the product design demonstrates its contribution to the (re)production of gender differences with which the material culture works. The reproduction of stereotypes is not conscious, but favors the maintenance of a differentiation system guided by socio-cultural backgrounds. In this article, we seek to interpret the design procedures from the perspective of semiotics, to understand how gender differences are constructed and to identify, through the analysis of some products, manifestations of characteristics socially assigned as male or female.
\end{abstract}


Finally, we observed initiatives that use the design as a means to blur gender boundaries.

Keywords: gender, industrial design, material culture, semiotics.

\section{INTRODUÇÃO}

No processo de design existe uma preocupação com as necessidades e anseios do público-alvo, e cabe ao designer decodificar estas necessidades, agregadas a um complexo conjunto de significados do contexto em que eles estão inseridos. As características inscritas no produto vão além da tecnicidade e funcionalidade, incluindo também conceitos socioculturais e valores individuais. Devemos então considerar o aspecto subjetivo dos produtos e sua capacidade de comunicação com o usuário, levando em conta que sua configuração é realizada por um designer que é sujeito integrante de uma realidade sociocultural. É possível então deduzir que um objeto não é formado apenas por fatores funcionais práticos, mas que funcionam também como símbolos.A preocupação com os problemas sociais raramente é posta como foco na criação de produtos, embora a cultura material tenha a capacidade de amenizá-los ou intensifica-los, pois os objetos possuem significado (MACHADO e MERKLE, 2010).

Adrian Forty (2008) exemplifica as metáforas das características de gênero na arquitetura, mais especificamente no formato das colunas gregas. A aparência da coluna dórica era considerada masculina, mais grave, sem ornamentos; a ordem jônica é esbelta e feminina como uma donzela; já a ordem coríntia apresenta a sensualidade de uma cortesã (FORTY apud WOTTON, 1964). Nesta metáfora de gênero, estão estabelecidos ideais distintos de masculinidade e feminilidade. A restrição dessas características a cada gênero veio a se apoiar em teorias científicas que também foram construídas para justificar a diferenciação sexual das capacidades de cada um (NUCCl, 2010), atribuindo tanto a homens quanto mulheres atividades e produtos específicos que reforcem tais características. Portanto, a hipótese que pretendemos problematizar é de que o design reproduz ou dissemina, por meio da significação dos objetos, ideias e conceitos sobre o que se entende por características masculinas e femininas. Procuramos também identificar os contextos e razões que levaram à criação de tais estereótipos.

Para delimitar a pesquisa em um determinado grupo de itens de consumo e concentrar os estudos de caso, definimos como categoria de análise os objetos industriais comercializados para o cuidado pessoal. Entende-se por produto para uso pessoal aquele cujo consumo é individual com pouca ou nenhuma possibilidade de compartilhamento, destinado à função de cuidado pessoal, podendo ser descartável ou de vida-útil média. A problemática com os objetos para cuidados pessoais foi iniciada pela observação de que existem no mercado produtos destinados a pessoas de determinado gênero ou sexo, que recorrentemente não apresentam diferenças funcionais. Podemos citar como exemplo as lâminas para depilação, que exercem a mesma função de forma satisfatória - quando de boa qualidade - independentemente da cor ou formato em que se apresentam na prateleira. Ainda assim, encontramos lâminas femininas em tons leves de cores como rosa e lilás, com formas curvilíneas e muitos ornamentos, enquanto o mesmo produto anunciado como masculino apresenta cores em tons mais escuros, vibrantes, formas futuristas e materiais que 
remetem ao metal. O que buscamos compreender neste trabalho é como estas ideias de masculinidade e feminilidade são inseridas no produto durante o processo de design, com a intenção de problematizar a naturalização das características de gênero difundidas em nosso ambiente cultural.

\section{DESENVOLVIMENTO}

\subsection{Design e linguagem}

Entre os diversos estudos teóricos sobre o design, discute-se muito sobre os possíveis objetivos de se pensar e projetar a estética de um produto. Encontramos argumentos que defendem desde que o que produzimos se aproxima de um valor artístico e belo, até que o foco do design está na resolução de problemas. Não podemos esquecer, porém, que a criação de produtos está ligada diretamente à sua comercialização e, consequentemente, espera-se que eles gerem lucro a quem produz (FORTY, 2013). Nesse sentido, é imprescindível que haja diversidade de produtos para que o usuário possa comprar mais, e o design é geralmente o catalisador desta vontade de compra. Segundo reportagem na página da Associação Brasileira de Supermercados, o consumidor aponta como fatores decisivos para a compra as formas e cores do produto ou de sua embalagem. Indo além da presença que os objetos exercem no cotidiano, os produtos específicos para cuidados pessoais possuem uma relação bastante aproximada com nossos corpos e intimidade, e não apenas os escolhemos pela identificação subjetiva, mas também por uma expectativa daquilo que podemos obter com ele. Esta mesma lógica pode ser aplicada para falar de outros produtos, e portanto é possível percebermos a influência do uso de objetos na construção de nossa própria subjetividade.

O senso comum tende a naturalizar certos conceitos e ideais frente a todas as manifestações da realidade que, embora não deixe de fazer parte do contexto em que vivemos, é construída historicamente. Estes ideais e conceitos nos quais nos baseamos para reagir e interpretar tudo à nossa volta são construídos por mitos que exprimem significados. O conceito "é simultaneamente, histórico e intencional; é móbil que faz proferir o mito" (BARTHES, 1975 p. 140). Na visão estruturalista, o objeto da semiologia é qualquer sistema que expresse significado, podendo também ser composto por objetos e imagens. Não têm um sentido, porém, sem que antes seja atribuído a eles um significado por meio da linguagem, sendo esta a mediadora da significação (BARTHES, 1974). Assim, se podemos afirmar que o mito é uma linguagem, também podemos enxergar esta função no design, já que interpretamos a aparência das coisas. Portanto, tal qual a mídia e a propaganda, o design exerce grande influência na maneira como vemos o mundo, deixando então de ser visto como mera expressão criativa, uma vez que "provoca efeitos muito mais duradouros do que os produtos efêmeros da mídia porque pode dar formas tangíveis e permanentes às ideias sobre quem somos e como devemos nos comportar" (FORTY, 2013 p. 12). A razão pela qual o mito é tão eficaz é que a realidade que ele produz nos parece tão natural que é confundida como não sendo historicamente construída (BARTHES, 1975). É um processo semelhante ao que acontece quando consumimos algum tipo de produto: o conceito que entendemos por meio de formas e cores é tão interiorizado e tão disseminado culturalmente, que nos parece que aquele objeto foi desenhado levando em consideração apenas a realidade natural das coisas. Propõe-se aqui que 
nem mesmo o próprio designer - ou empresa responsável pela definição do briefing faça esta transposição de ideias conscientemente, com a intenção direta de manipular e transmitir seus próprios valores para o usuário. Entretanto, especificamente no caso dos mitos de masculinidade e feminilidade, não podemos desconsiderar o contexto patriarcal de formação de profissionais e da construção de padrões e parâmetros para o design (BUCKLEY, 1986).

Em História da Sexualidade I (2015), Foucault critica a hipótese de que o poder manifesta seu controle de forma proibitiva, reprimindo e silenciando o discurso sobre o sexo. Ao invés disso, defende uma dimensão produtora dos mecanismos de poder, que regulam a sexualidade através de técnicas discursivas e se apoiam $\mathrm{n}$ a produção do saber. Dessa forma, para além de censurar-se as falas sobre o sexo, as formas modernas do poder agem na (re)produção incessante da sexualidade e do binarismo de gênero. (FOUCAULT, 2015). O poder é, portanto, um produtor de discurso e nós funcionamos como reprodutores deste, fazendo parte da manutenção do dispositivo. Mesmo indiretamente, o discurso de poder se manifesta em todo o espectro social: relações privadas, classes, grupos, informações, comunicação. O poder está presente na linguagem, sendo esta uma forma de percebê-lo: a própria forma como a língua é estabelecida reflete o discurso de poder, à medida que as mensagens são conformadas a ser expressas dentro de uma determinada forma (BARTHES, 2015).

Partindo desta leitura relacionada entre design e linguagem, propõe-se que o design também pode ser um instrumento político para a disseminação de ideias e, se podemos transmitir ideais sexistas de masculinidade e feminilidade, também é possível uma resistência às fronteiras binárias por meio do design.

\subsection{A construção das diferenças de gênero}

A classificação ou ordenação do mundo é característica presente em toda cultura. Pode apresentar-se de forma complexa ou simplificada em sua lógica, mas o ato de encaixar o mundo em categorias está sempre presente.Teresa de Lauretis (1994, p.207) define diferença sexual como conceitos abstratos que obtemos acerca do que é masculino e feminino, mas principalmente a diferença da mulher em relação ao homem. Esta classificação é feita no campo do inconsciente político, que é perpetuado pela sociedade como um todo, inclusive pelas mulheres. As denominadas tecnologias de gênero representam as características e os ideais de cada gênero e contribuem para a continuidade deste modelo regulatório. Ao classificar os indivíduos por gênero, os posicionamos dentro de um grupo social, ao qual a escolha de se pertencer não é livre, mas também não é por uma coerção inteiramente externa e arbitrária. Dentro de uma cultura, a noção de que o masculino e o feminino são distintos e se complementam simbolicamente atribui a cada sexo um conjunto de conteúdos sociais, valores e hierarquias (LAURETIS, 1994 p. 211).

Muitas das características estereotípicas relacionadas ao sexo dos indivíduos vêm de como é representada culturalmente a manifestação da sexualidade em cada um. Em referência a Lucy Bland (1981), Lauretis cita que "a polaridade 'masculino/feminino' tem sido e ainda é um dos temas centrais de quase todas as representações da sexualidade (...) a sexualidade masculina é considerada ativa, espontânea, genital, facilmente suscitada por 'objetos' (...) a sexualidade feminina é vista em termos de sua relação com a sexualidade masculina". Não é inesperado que, 
em uma sociedade patriarcal como a nossa, o masculino seja a referência a partir da qual classificamos as diferenças sexuais. O próprio conceito de mulher é constantemente criado e modificado por discursos que precedem o design, e por ele mesmo.

Para separar do aspecto do sexo biológico as construções subjetivas de homens e mulheres, utiliza-se o termo gênero (GOODALL, 1990). Entretanto, para Judith Butler (2000), não é possível desassociar a própria diferença sexual das práticas discursivas, o que não quer dizer que tais práticas criam a diferença "do nada", mas que ela depende do discurso para ser marcada e instaurada. O sexo é também normatizado - para garantir a hegemonia de um sistema binário heterossexual - e depende de atos de performatividade para reiterar o discurso e produzir efeitos regulatórios no corpo físico. Dessa forma, o gênero não deve ser entendido apenas "como um construto cultural que é simplesmente imposto sobre a matéria (...) Ao invés disso, uma vez que o próprio 'sexo' seja compreendido em sua normatividade, a materialidade do corpo não pode ser pensada separadamente da materialização daquela normal regulatória" (BUTLER, 2000).

A vida dos homens e mulheres de classes média e alta do século XIX era acentuadamente dividida: à mulher cabia a função de receber visitas e dedicar-se à maternidade, enquanto ao homem cabiam funções de comando e decisões políticas, pois julgava-se que possuíam qualidades como força e retidão (FORTY, 2013). Segundo Laqueur, citado na dissertação de Marina Nucci (2010), a ideia científica de diferenciar os sexos começa a partir do final do século XVIII, onde até então predominava um sistema de "sexo único", onde o homem era visto como o ser humano original que possuía uma inversão - a mulher - cujos órgãos sexuais eram internos devido à falta de calor. Acreditava-se, inclusive, que seria possível um corpo feminino transformar-se em masculino quando recebesse calor. O inverso, porém, não era possível, uma vez que também era afirmado que a natureza ia sempre em direção à perfeição. Justamente na época em que começam a ocorrer lutas políticas por uma mudança no papel da mulher, o movimento da ciência é justamente de separar cada segmento do corpo entre masculino e feminino, tornando a fisiologia completamente distinta de acordo com o sexo. A anatomia do corpo feminino começa a ser utilizada como recurso para justificar sua inferioridade, relegando às mulheres apenas o papel da maternidade e excluindo-as da vida pública (NUCCl apud SCHIEBINGER, 2010). Novamente referenciando Laqueur, Nucci explicita que a anatomia não deve ser vista como algo que estava simplesmente posto e que fora então descoberto, mas sim que a ciência também constrói seu conhecimento de acordo com o viés do pensamento hegemônico na sociedade. Atualmente, vigora na comunidade científica uma reprodução de estereótipos de masculinidade e feminilidade justificando-os com base em uma suposta diferenciação sexual do cérebro (NUCCl apud WIJINGAARD, 2010). Outra autora feminista da área da biologia citada por Nucci, Ruth Bleier (1988), critica tal determinismo biológico, não no sentido de negar a biologia, mas afirmando haver entre esta e a cultura uma interação que influencia com um viés androcêntrico a interpretação de experimentos.

Como mencionado anteriormente em relação à criação de mitos, podemos notar que existe uma tendência de se confundir história e natureza, o que leva o senso comum a encarar a ciência biológica como algo que estava presente anteriormente na 
natureza, aguardando seu descobrimento, sem levar em consideração que até mesmo a nossa interpretação da natureza é histórica, social e política.

\subsection{Diferenciação sexual em produtos para cuidados pessoais}

As afirmações de diferença sexual, mais comuns durante o século XIX, são ideias que para serem naturalizadas contam com mecanismos de construção do saber como a educação formal, a religião, a mídia e o design. Este último contribui com a caracterização dos objetos feita a partir dos estereótipos de gênero definidos e, por não basear-se tanto nas palavras, mas sim em signos visuais, oferece "sinais duradouros, visíveis e tangíveis das diferenças entre homens e mulheres tal como se acreditava que existissem" (FORTY, 2013 p. 95).

Para Cheryl Buckley (1986), uma das razões que leva o design a produzir diferenciações é o viés que exclui as mulheres na história do design. As poucas que são citadas na literatura sobre o design são definidas, devido ao seu gênero, como usuárias de produtos femininos ou têm seu nome colocado abaixo de seus maridos, irmãos ou pais. O papel da mulher em alguns setores do design, ainda segundo a autora, é travado pelos estereótipos criados no patriarcado, que possui respaldo nas teorias científicas citadas anteriormente, que foram utilizadas como justificativas para relegar determinados papéis sociais e profissionais para as mulheres. O que Buckley argumenta é que, para entender a situação das mulheres em relação ao design - tanto como criadoras quanto como usuárias - é preciso lembrar que este foi criado no contexto patriarcal e que, portanto, "os ideais de habilidades e necessidades do design para as mulheres tem sua origem no patriarcado" (BUCKLEY, 1986 p. 4). Buckley afirma que, neste contexto, considera-se que mulheres possuem determinadas habilidades como meticulosidade, destreza e ornamentação, "o que faz com que elas estejam naturalmente aptas a certas áreas da produção do design", como joalheria, bordado, ilustração e cerâmica, para citar algumas. Poderíamos citar também a produção de roupas, e argumentar que a indústria da moda também possui muitos homens trabalhando em sua produção, porém o lugar que eles ocupam normalmente é visto com maior sofisticação; basta lembrar que grande parte dos nomes mais famosos desta indústria são de homens: Christian Dior, Louis Vuitton, Karl Largefeld, Alexander Mcqueen. O que Buckley propõe como discussão é o entendimento de que a justificativa da predisposição biológica é também uma criação do contexto patriarcal, e que é preciso entender as razões pelas quais certas habilidades e necessidades são atribuídas às mulheres como designers ou consumidoras, em função de uma definição histórica que associa a mulher ao serviço doméstico e dedicação ao casamento e à maternidade. Tais estereótipos são comumente reforçados também pela propaganda, que associa o produto ao seu usuário ideal.

A diferenciação sexual, reforçada principalmente ao longo do final do século XVIII (NUCCl, 2010), sedimentou a posição social da mulher como um ser de corpo fragilizado, emocional e dependente, não muito propício para a inteligência e a atividade. Por outro lado, o homem mantinha sua posição como um ser ativo, viril e capaz de controlar as emoções e agir racionalmente. Portanto, quando extrapolamos estas descrições estereotípicas dos sexos para o aspecto visual do produto encontramos características descritas como "ornamentada, delicada e curvilínea", que devem ser evitadas quando há a necessidade de expressar imponência, poder e 
admiração. Neste caso, as formas ditas masculinas apresentam firmeza, grandeza, planos retilíneos, ângulos retos, poucos detalhes ornamentais e são consideradas adequadas na arquitetura (FORTY apud BLONDEL, 2008).

Entre os produtos para cuidado pessoal, exemplificaremos esta diferenciação utilizando as lâminas da marca Gillette, em suas linhas Body e Venus, atribuídas, respectivamente ao público masculino e ao feminino. Escolhemos fazer a comparação destes, pois tradicionalmente existe uma diferença entre as lâminas femininas e masculinas, porém esta diferença se encontra normalmente no uso pretendido, onde estaria implícito que homens as utilizam apenas para o barbear, enquanto as mulheres fariam a depilação em outras partes do corpo como axilas e pernas. Ou seja, a diferença sexual aparece no produto devido às diferenças nas técnicas de cuidado do corpo, que são aprendidas em sociedade. Quando a Gillette comercializa uma linha masculina com o nome Body - corpo, em inglês - parece buscar adaptar-se a uma tendência recente de cuidados com o corpo em que o homem passa a também depilar outras partes do corpo além do rosto, como tórax, pernas e axilas. Porém, permanece oferecendo as duas opções de produtos diferenciadas pelo sexo e acompanhadas de signos visuais que deixam claro qual produto é destinado a quem. Embora o formato em si não apresente tanta diferença ao olhar, a escolha das cores é evidentemente diferente. No produto masculino predomina o uso do preto que, de uma forma geral, é uma cor frequentemente associada a produtos masculino e não por acaso passa a impressão de ser uma cor pesada e sóbria.

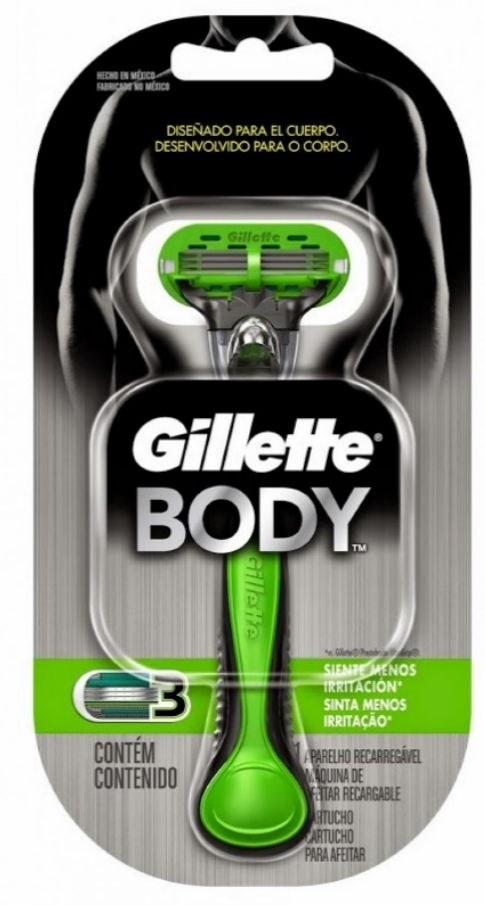

Figura 1 - Gillette Body

Fonte: <http://www.cosmeticanews.com.br/_imagens/noticias/gillette-apresenta-o-novo-gillette-bodycriado-para-a-superficie-do-corpo-masculino_1.jpg>

Enquanto isso, as cores do produto feminino se apresentam em tons mais iluminados com maior adição de branco, podendo ser associadas à leveza. A embalagem também desempenha uma função diferenciadora relevante, uma vez que sua linguagem visual associa objetos masculinos a metais, e femininos à água. A 
própria diferenciação da tipografia da marca determina o sexo ao qual o produto é destinado. Ambas pertencem à mesma marca, porém a variação Venus apresenta uma fonte curvilínea, deixando em segundo o plano a marca Gillette, que possui uma tipografia retilínea e em itálico - afinal, trata-se de lâminas que cortam. A marca principal é, porém, apresentada em primeiro plano na embalagem do produto masculino, contribuindo com a ideia que se faz de objetos masculinos.
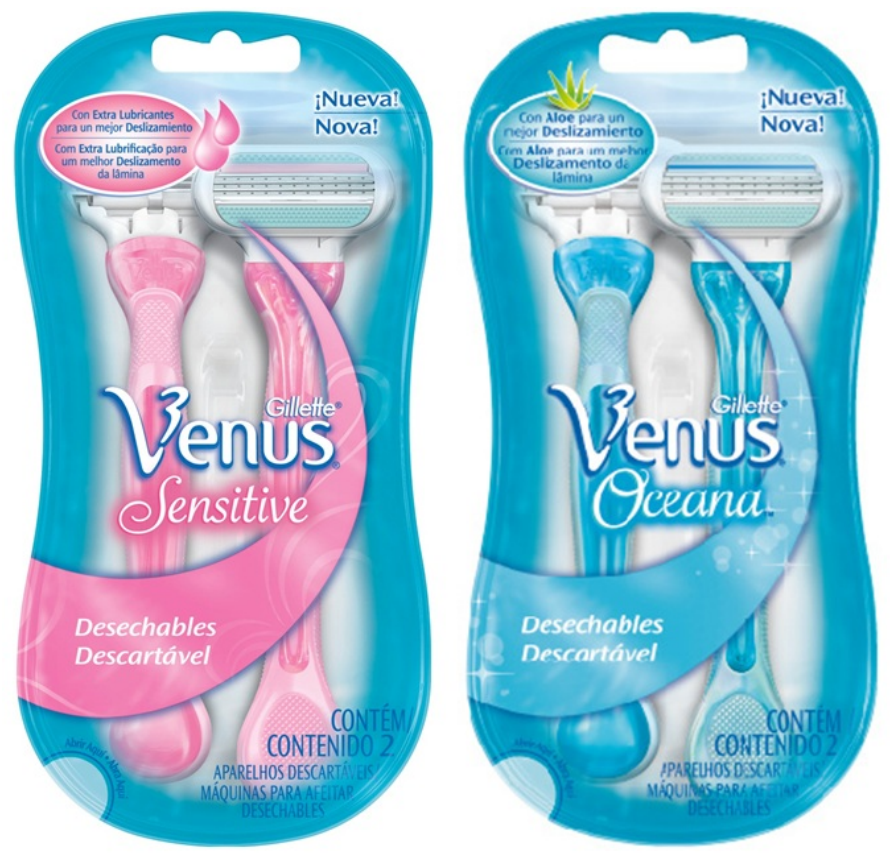

Figura 1 - Gillette Venus

Fonte: <http://makeupyourstyles.com.br/wpcontent/uploads/2012/09/VENUS_SO.jpg>

Como consequência de sua dissertação de mestrado, a designer finlandesa Saana Hellsten (2013) idealizou um projeto que propunha criar um conceito de embalagens que neutralizasse o gênero das lâminas oferecidas no mercado, contribuindo assim para uma sociedade mais receptiva à diversidade de gênero. Após analisar as diferenças de gênero na cultura visual, Saana desenvolveu o projeto conceitual BASIK, que procura unificar a identidade dos produtos e oferecer ao consumidor a possibilidade de escolher o produto pela função que será desempenhada por ele, não pelo gênero para o qual ele é designado. Neste conceito, a lâmina de barbear poderia ser selecionada pelo tipo de cabo, cabeça e área do corpo a ser depilada, disponível em um espectro de cores e tons variados. Esta iniciativa integra uma tendência atual em que marcas procuram demonstrar uma visão de maior diversidade de gênero, a exemplo de marcas como Louis Vuitton, que recentemente utiliza o ator Jaden Smith em sua campanha feminina, e a Zara, que lançou a coleção Ungendered. Neste último caso, a solução é passível de crítica, uma vez que a marca optou pela criação de peças que mantêm um aspecto mais tradicionalmente masculino e básico, sem a presença de saias ou vestidos, por exemplo. ${ }^{1}$

\footnotetext{
${ }^{1}$ Fonte: GQ Brasil. "Zara entra na discussão do fim da divisão de gêneros com linha unissex", por Vinicius Guidini. 6 mar. 2016.

Disponível em: < http://gq.globo.com/Estilo/Moda-masculina/noticia/2016/03/zara-entra-na-discussaodo-fim-da-divisao-de-generos-com-linha-unissex.html> Acesso em: 27 abr. 2016
} 
Na premiação Wave Festival in Rio, que ocorreu nos dias 13 e 14 de abril no Rio de Janeiro, a categoria Design teve como um dos premiados com bronze a campanha da Agência Fischer, intitulada The Badass Shampoo Bottle, que anuncia uma embalagem de xampu para homens inspirada em garrafas de cerveja. ${ }^{2} \mathrm{~A}$ campanha associa ao público masculino algumas atividades como cortar lenha, enquanto comprar xampu é apresentado como algo tradicionalmente feminino e motivo de riso entre homens quando estes precisam realizar tal atividade. A criação deste tipo de produto demonstra que uma das funções do design é reforçar não apenas estereótipos na sociedade, mas também contribui para que o próprio usuário reafirme aquilo que quer associar a si mesmo. Nesse caso, ao criar uma embalagem de xampu para homens cuja inspiração é a cerveja - que também faz parte do imaginário do que são as coisas que um homem deve gostar - o designer possibilita que o consumidor escolha o produto buscando sentir-se mais másculo. No entanto, o que permanece em dúvida é o quão frágil é essa noção estereotípica de masculinidade que é abalada simplesmente pela compra de um xampu.

\section{CONCLUSÃO}

Uma análise de produtos industriais encontrados atualmente no mercado demonstra que a divisão dos produtos apoia-se muito no gênero do público-alvo. A variabilidade de produtos é considerada necessária para a identificação subjetiva do consumidor com o produto e para provocar uma sensação de exclusividade que é importante na estratégia de venda. No entanto, a forma como reproduzimos os conceitos e ideais nos produtos também deve ser observada como parte de nosso contexto social e histórico, ao contrário de uma naturalização simples apoiada em uma interpretação de natureza que também é histórica.

Sob ponto de vista das questões de gênero, produtos desenvolvidos sem preocupação social podem reproduzir valores sexistas e alimentar uma cultura patriarcal ou heteronormativa, o que pode acontecer mesmo que a designer se identifique como mulher, pois a reprodução sexista das diferenças de gênero não se dá no plano das vontades controláveis e da consciência. A definição e reprodução destes ideais não é feita de forma necessariamente intencional, mas não é possível desconsiderar a influência histórica e social que nos levou a criar tais mitos e disseminá-los por meio de nossa linguagem e educação. A própria definição dos parâmetros para o que se entende por um "bom design", por ter sido historicamente definida dentro do contexto da sociedade patriarcal, tende a assumir características masculinas. Uma vez que todos fazemos parte deste contexto de sociedade patriarcal, tanto homens quanto mulheres (BUCKLEY, 1986), iniciativas que procurem neutralizar as diferenças sexuais são uma forma de resistência à hegemonia do sistema binário e heterossexual. O design - sobretudo de produtos para cuidado pessoal - consegue alcançar o usuário e fazer parte do seu cotidiano e de sua relação com o próprio corpo, sendo possível considera-lo também uma possível via de resistência.

2Fonte: Wave Festival in Rio. “Brasil conquista 10 prêmios em Design”, por Teresa Levin. 13 abr. 2016. Disponível em: <http://www.wavefestival.com.br/cobertura2016/2016/04/13/brasil-conquista-10premios-em-design/> Acesso em: 27 abr. 2016 


\section{REFERÊNCIAS}

ABRAS (Associação Brasileira de Supermercados). Embalagens certas podem elevar vendas de produtos. 2012. Disponível em:

<http://www.abrasnet.com.br/clipping.php?area=1\&clipping=30110> Acesso em: 25 Ago. 2015.

BARTHES, Roland. Aula. São Paulo: Cultrix, 2015

BARTHES, Roland. Elementos da semiologia. São Paulo: Cultrix, 1974.

BARTHES, Roland. Mitologias. São Paulo: Difel, 1975.

BUCKLEY, Cheryl. Made in patriarchy: toward a feminist analysis of women and design. Design Issues, Vol. 3, no 2, p. 3-14. 1986. Disponível em:

<http://www.jstor.org/stable/1511480> Acesso em: 19 abr. 2016

BUTLER, Judith. Corpos que pesam:sobre os limites discursivos do "sexo". Tradução: Tomaz Tadeu da Silva. In: LOURO, Guacira Lopes (Org.). 0 corpo educado: pedagogias da sexualidade. Belo Horizonte: Autêntica, 2000.

FORTY, Adrian. Masculino, feminino ou neutro? In: Arte \& Ensaios, Escola de Belas Artes, UFRJ. Rio de Janeiro, 2008. p. 134-143. Disponível em: < http://www.ppgav.eba.ufrj.br/wp-content/uploads/2012/01/ae16_Adrian_Forty.pdf> Acesso em: 25 ago. 2015.

FORTY, Adrian. Objeto de desejo. São Paulo: Cosac Naify, 2013.

FOUCAULT, Michel. História da Sexualidade I: A vontade de saber. São Paulo: Paz e Terra, 2015.

GOODALL, Philippa. Design and Gender: Where is the Heart of the Home? Built Environment, Vol. 16, № 4, Women and the Designed Environment. 1990. p. 269-278. Disponível em: < http://www.jstor.org/stable/23286228 > Acesso em: 23 abr. 2016

HELLSTEN, Saana. BASIK. Nova lorque: Pratt Institute, 2013. Disponível em: <http://saanahellsten.com/> Acesso em: 27 abr. 2016

LAURETIS, Teresa de. A tecnologia do gênero. In: BUARQUE DE HOLLANDA, Heloísa (Org.). Tendências e Impasses: o feminismo como crítica da cultura. Rio de Janeiro: Rocco, 1994. p. 206-242.

MACHADO, Renata Silva Santos e MERKLE, Luiz Ernesto. As relações existentes entre o fazer design com base nas questões de gênero. In: VIII Congresso ibero-americano de Ciência, Tecnologia e Gênero. Curitiba, 2010. Disponível em: < http://files.dirppg.ct.utfpr.edu.br/ppgte/eventos/cictg/conteudo_cd/E10_As_Rela\%C3 \%A7\%C3\%B5es_Existentes_entre_o_Fazer_Design.pdf> Acesso em: 25 ago. 2015.

NUCCl, Marina Fisher. Hormônios pré-natais e a ideia do sexo cerebral: uma análise das pesquisas biomédicas sobre gênero e sexualidade. 2010. 104 f. Dissertação (Mestrado) - Universidade Estadual do Rio de Janeiro, Programa de Pós-Graduação em Saúde Coletiva. Disponível em: <http://www.bdtd.uerj.br/tde_arquivos/44/TDE-201009-02T083950Z-878/Publico/NUCCI,\%20Marina.pdf> Acesso em: 27 abr. 2016. 